\title{
Epstein Barr virus in Hodgkin's Lymphoma a Path Less Treaded: An Observational study
}

\author{
Kirti Balhara ${ }^{1}$, Sarika Singh ${ }^{1 *}$, Shyamlata Jain ${ }^{1}$, M.K. Daga ${ }^{2}$ and Anubhav Vindal ${ }^{3}$ \\ ${ }^{1}$ Department of Pathology, Maulana Azad Medical College, Delhi, INDIA \\ ${ }^{2}$ Department of Medicine, Maulana Azad Medical College, Delhi, INDIA \\ ${ }^{3}$ Department of Surgery, Maulana Azad Medical College, Delhi, INDIA
}

\begin{abstract}
Background: Epstein-Barr virus (EBV) is a ubiquitous virus belonging to $\gamma$-Herpesvirus subfamily, infecting B cells, T cells, Natural killer (NK) cells \& causes both benign and malignant diseases. It has been detected in large subset of Hodgkin lymphoma (HL) cases around the world, especially in countries with poor socioeconomic conditions and among younger age. Limited studies are available reflecting the Indian scenario of HL and EBV association. EBV positivity in Indian HL varies from 28-97\% Majority of these studies employed Immunohistochemistry (IHC) for LMP1, a few performed In Situ Hybridisation (ISH) for EBER.

Objective: To study the association of EBV in classical HL by immunohistochemical expression of latent membrane protein 1 (LMP1) antigen in North Indian population and to correlate it with different demographic variables \& subtypes of HL.

Materials and Methods: Observational study including 26 untreated HL cases diagnosed on lymph node excision biopsy. IHC was performed for EBV LMP1, CD15, CD30,CD45, CD3, CD20.

Results: Patients ranged in age from 5-55years (median 18yrs), with M:F ratio of 3.3:1. Palpable lymphadenopathy was found in all cases followed by pallor (64\%), B symptoms (50\%), nodal pain (30.8\%) \& bulky disease (19.2\%). Maximum number of patients were in Stage I (65.4\%) followed by stage II\&III (15.4\% each) \& stage IV (3.8\%). Mixed cellularity HL comprised $77 \%$, lymphocyte depleted $11.5 \%$, nodular sclerosis $7.7 \%$ \& lymphocyte rich $3.8 \%$. IHC for EBV LMP1 was positive in $73.1 \%$ cases. Mixed cellularity HL showed an association in $70 \%$ cases.
\end{abstract}

Conclusions: HL in India is a disease of young males, with mixed cellularity as the commonest subtype, highly associated with EBV and presentation at an early stage.

Keywords: Hodgkin Lymphoma, EBV, LMP1

\section{Introduction}

Epstein-Barr virus (EBV) ,a member of $\gamma$-Herpesvirus subfamily, infects B cells, T cells, Natural killer(NK) cells and establishes a lifelong latent infection in B cells. ${ }^{[1]} \mathrm{EBV}$ positivity of $30-50 \%$ is found in patients from developed countries, whereas it is seen in nearly $100 \%$ of children belonging to developing countries. ${ }^{[2]}$ In India, burden of EBV positivity is very high and many malignancies are found to be associated with it. Studies from Indian subcontinent shows EBV positivity in Hodgkin lymphoma (HL) ranging from $31-82 \%$ in all ages, and $28-98 \%$ amongst paediatric population, established primarily by employing IHC for EBV-LMP1. ${ }^{[3-7]} \mathrm{EBV}$ association with HL has a bearing on Overall Survival (OS) / Disease Free Survival(DFS) of patients and thus warrants more stringent chemotherapy, therefore EBV profiling is essential as targeted therapy in the form of Rituximab is to be introduced accordingly.

The present study aims to assess the expression of EBV in $\mathrm{HL}$ in North Indian population and to further detect EBV in various demographic variables and subtypes of HL.

\section{Materials and Methods}

A cross sectional prospective study was undertaken over a period of one year, including $26 \mathrm{HL}$ cases for which lymph node excision biopsies were conducted following guidelines of the institutional ethics committee. An informed consent was obtained from all patients. All newly diagnosed and untreated cases of HL were included while all other haematolymphoid malignancies were excluded. Detailed clinical history which included history of unexplained weight loss, unexplained fever, chest pain, cough, shortness of breath, pruritis, pain at nodal site, bone pain, past history of prolonged illness and family history were taken. All relevant history of the lymph node swelling with respect to mode of onset, duration, progression, association with trauma or pain, whether accompanied by similar swelling elsewhere in the body or in the past were noted. History of secondary changes like softening, ulceration, fungation or inflammatory changes was also inquired. General physical examination and a local examination was done in terms 
of site, size, shape, colour, surface, number, consistency, overlying skin, local temperature, and tenderness of lymph nodes.

The tissue received as lymph node excision biopsy was grossed and routinely processed. Formalin fixed paraffin embedded (FFPE) blocks were made after routine processing in automated tissue processor. Four-micron thick sections were cut from the paraffin block. The slides were stained with haematoxylin and eosin and their morphology studied. Tumour was characterized taking into account the histomorphology, lymph node architecture, presence of Reed-Sternberg/Hodgkin (RS/H) cells and accompanying inflammatory milieu of cells. The buffers used were phosphate-buffered saline (PBS) with a $\mathrm{pH}$ of 7.0 for staining and citrate buffer with a $\mathrm{pH}$ of 6.0 for antigen retrieval.

The various IHC markers used were: EBV-LMP1 (Dako, RTU), CD15 (Skytek, RTU)), CD30(Skytek, RTU), CD45 (Skytek, RTU), CD3 (Novocastra, RTU), CD20 (Skytek, RTU)

Immunopositivity was determined under light microscopy first at X40 and subsequently at higher magnification. CD15 and CD30 were considered positive when cells showed membranous and cytoplasmic dot like reactivity with golgi zone accentuation. Even one unequivocal RS/H cell showing membranous and cytoplasmic dot positivity with granular character and golgi zone accentuation was considered positive for LMP1. ${ }^{[8]}$

\section{Results}

Demographic Profile The age of patients ranged from 5 to 55 years with a median age of 18 years. Out of 26 cases, 20 cases occurred in males and six in females with a male:female ratio of 3.3:1.
Age range for Mixed cellularity HL(MCHL) cases was 5 to 46 years with median age of 17 years. In the patients with Nodular sclerosis HL(NSHL) age range was 7 to 16 years with median age of 11.5 years. In Lymphocyte rich (LRHL) age of the patient was 14 years. In Lymphocyte depleted (LDHL) age ranged from 20 to 55 years with median age of 34years.

Out of the 26cases of classical Hodgkin lymphoma (cHL) $20(76.9 \%)$ were classified as MCHL,02 $(7.7 \%)$ as NSHL, $01(3.8 \%)$ as LRHL and $03(11.5 \%)$ as LDHL.

Of the 20 cases belonging to MCHL,14(70\%) occurred in males and 06(30\%) in females. All cases classified as NSHL, LRHL \&LDHL occurred exclusively in males.

Clinical Profile The most common presenting complaint seen in patients was of unexplained fever \& weight loss seen in $13 / 26$ cases(50\%), followed by pain at nodal site in $08 / 26$ cases $(30.8 \%$ ), cough \& pruritis in $03 / 26$ cases(11.5\%), shortness of breath in $02 / 26(7.7 \%) \&$ bone pain in $01 / 26$ cases $(3.8 \%)$.

On general physical examination pallor was noted in 16 cases $(64 \%)$, icterus was noted in 02 cases $(08 \%)$ and clubbing in 01 case (04\%). All cases had palpable lymphadenopathy (LAP).In two cases $(08 \%)$ hepatosplenomegaly was also noted whereas bulky disease (size $\geq 7 \mathrm{~cm}$ ) was seen in five cases(19.2\%).Ten cases had LAP for less than six months duration. In thirteen cases LAP was present for 6-12 months. Three cases had LAP for more than one year. Thus maximum number of patients $(>50 \%)$ had LAP for less than one year duration.

Clinical Staging was noted as per Ann Arbor classification for Hodgkin Lymphoma. (Table1)

Age wise distribution and correlation of EBV status with stage in various subtypes was noted in Table $2 \&$ Table 3 respectively.

Table 1: Ann Arbor classification for Hodgkin Lymphoma.

\begin{tabular}{|c|c|c|c|}
\hline \multirow{2}{*}{ Stage } & & Number of cases & Percentage \\
\hline \multirow{2}{*}{ Early } & $\mathrm{n}$ & & $\%$ \\
\hline \multirow{2}{*}{ Advanced } & $\mathrm{I}$ & 17 & 65.4 \\
\cline { 2 - 4 } & $\mathrm{II}$ & 4 & 15.4 \\
\cline { 2 - 4 } & III & 4 & 15.4 \\
\hline
\end{tabular}

Table 2: Age wise distribution of various subtypes.

\begin{tabular}{|c|c|c|c|c|c|c|}
\hline \multirow{2}{*}{ Subtype } & $\mathbf{0 - 1 0 y r s}$ & $\mathbf{1 1 - 2 0 y r s}$ & $\mathbf{2 1 - 3 0 y r s}$ & $\mathbf{3 1 - 4 0 y r s}$ & $\mathbf{4 1 - 5 0 y r s}$ & $\geq 51 \mathrm{yrs}$ \\
\cline { 2 - 7 } & $\mathbf{n}$ & $\mathbf{n}$ & $\mathbf{n}$ & $\mathbf{n}$ & $\mathbf{n}$ & $\mathbf{n}$ \\
\hline MCHL & 6 & 9 & 1 & 3 & 1 & 0 \\
\hline NSHL & 1 & 1 & 0 & 0 & 0 & 0 \\
\hline
\end{tabular}




\begin{tabular}{|c|c|c|c|c|c|c|}
\hline \multirow{2}{*}{ Subtype } & $\mathbf{0 - 1 0 y r s}$ & $\mathbf{1 1 - 2 0 y r s}$ & $\mathbf{2 1 - 3 0 y r s}$ & 31-40yrs & $\mathbf{4 1 - 5 0 y r s}$ & $\mathbf{2 5 1 y r s}$ \\
\cline { 2 - 7 } & $\mathbf{n}$ & $\mathbf{n}$ & $\mathbf{n}$ & $\mathbf{n}$ & $\mathbf{n}$ & 0 \\
\hline LRHL & 0 & 1 & 0 & 0 & 0 & 1 \\
\hline LDHL & 0 & 1 & 0 & $\mathbf{0 4}$ & $\mathbf{0 1}$ \\
\hline Total(26) & $\mathbf{0 7}$ & $\mathbf{1 2}$ & $\mathbf{0 1}$ & $\mathbf{0 1}$ \\
\hline
\end{tabular}

Table 3: Correlationof EBV-LMP1 status with stage in various subtypes of HL.

\begin{tabular}{|c|c|c|c|c|c|c|c|c|c|c|}
\hline \multirow{2}{*}{$\begin{array}{c}\text { SUBTYPE } \\
\text { EBV-LMP1 } \\
\text { STATUS }\end{array}$} & \multicolumn{2}{|c|}{$\begin{array}{c}\mathrm{MCHL}, \mathrm{N}=20 \\
\mathrm{n}(\%)\end{array}$} & \multicolumn{2}{|c|}{$\begin{array}{c}\text { NSHL, } N=2 \\
n(\%)\end{array}$} & \multicolumn{2}{|c|}{$\begin{array}{c}\text { LRHL, } N=1 \\
n(\%)\end{array}$} & \multicolumn{2}{|c|}{$\begin{array}{c}\text { LDHL, } N=3 \\
n(\%)\end{array}$} & \multicolumn{2}{|c|}{$\begin{array}{c}\text { TOTAL, } \mathrm{N}=26 \\
\mathrm{n}(\%)\end{array}$} \\
\hline & + & - & + & - & + & - & + & - & + & - \\
\hline $\begin{array}{c}\text { STAGE I } \\
\mathrm{N}=17\end{array}$ & $9(34.6)$ & $4(15.4)$ & $1(3.8)$ & 0 & $1(3.8)$ & 0 & $2(7.7)$ & 0 & $13(76.5)$ & $4(23.5)$ \\
\hline $\begin{array}{l}\text { STAGE II } \\
\mathrm{N}=4\end{array}$ & $1(3.8)$ & $2(7.7)$ & $1(3.8)$ & 0 & 0 & 0 & 0 & 0 & $2(50)$ & $2(50)$ \\
\hline $\begin{array}{l}\text { STAGE III } \\
\quad \mathrm{N}=4\end{array}$ & $4(15.4)$ & 0 & 0 & 0 & 0 & 0 & 0 & 0 & $4(100)$ & 0 \\
\hline $\begin{array}{l}\text { STAGE IV } \\
\mathrm{N}=1\end{array}$ & 0 & 0 & 0 & 0 & 0 & 0 & 0 & $1(3.8)$ & 0 & $1(100)$ \\
\hline TOTAL & $14(70)$ & $6(30)$ & $2(100)$ & 0 & $1(100)$ & 0 & $2(67)$ & $1(33)$ & $19(73.1)$ & $7(26.9)$ \\
\hline
\end{tabular}

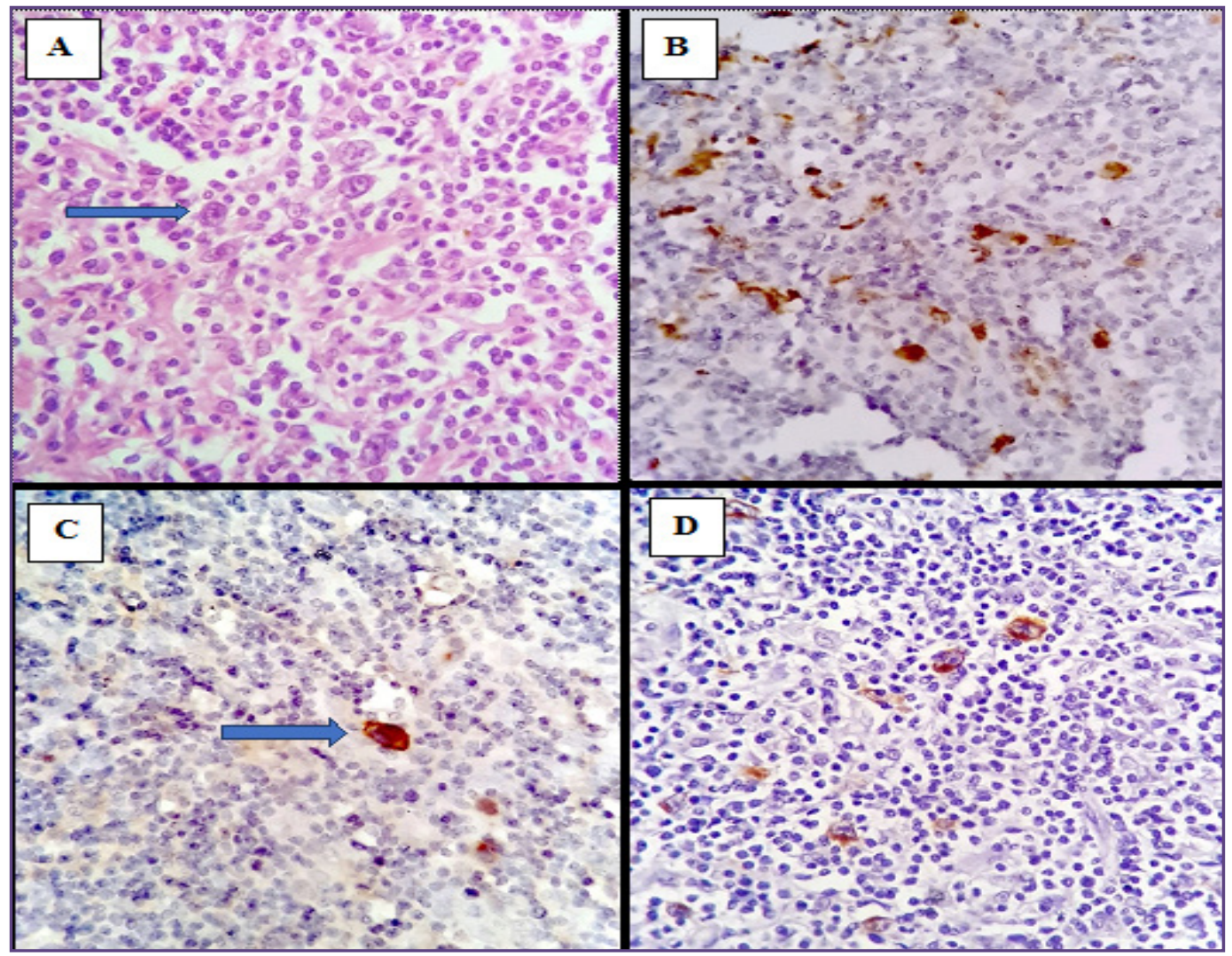

Fig. 1: A: Mixed cellularity HL (H\&E: X600 magnification), Mononuclear Hodgkin cell(arrow marked) in a mixed reactive cellular background., Figure 1B: Mixed cellularity HL (CD15: X600 magnification) RS cells showing CD15 positivity.; Figure 1C: Mixed cellularity HL (CD30: X600 magnification)Classical membranous andperinuclear dot like positivity in a binucleate RS cell (arrow); Figure 1D: Mixed cellularity HL (EBV-LMP1: X600)H/RS cells showing membranous and perinuclear dot like positivity for EBV-LMP1. 


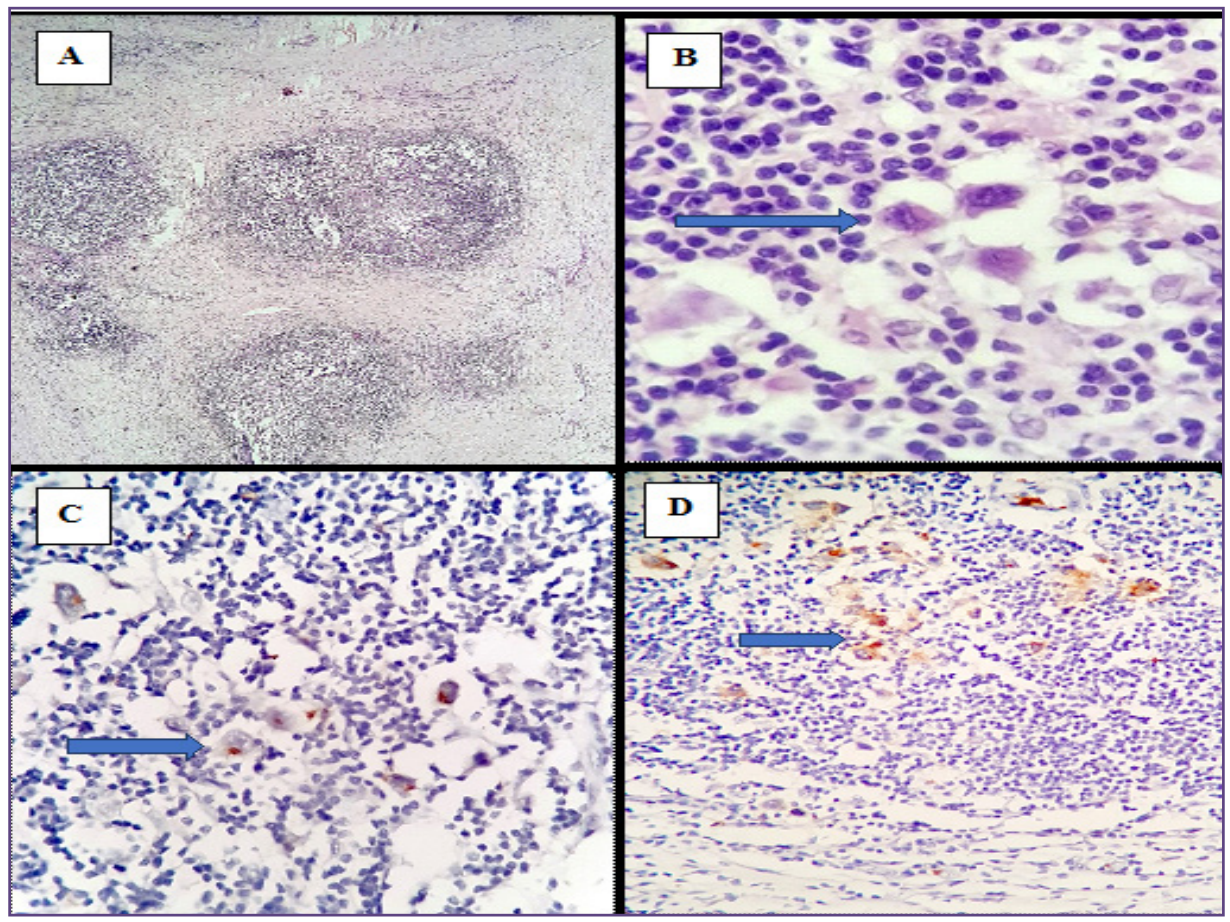

Fig. 2A: Nodular sclerosis (H\&E: X40 magnification), Fibrous collagen bands divide the lymph node into nodules.; Figure2B: Nodular sclerosis H\&E: X600, lacunar cells are seen (arrow).; Figure2C: Nodular sclerosis (CD30: X600 magnification) Lacunar cells show CD30 positivity(arrow).; Figure 2D: Nodular sclerosis (EBV-LMP1: X400 magnification) Positive for EBVLMP1 in lacunar cells(arrow).

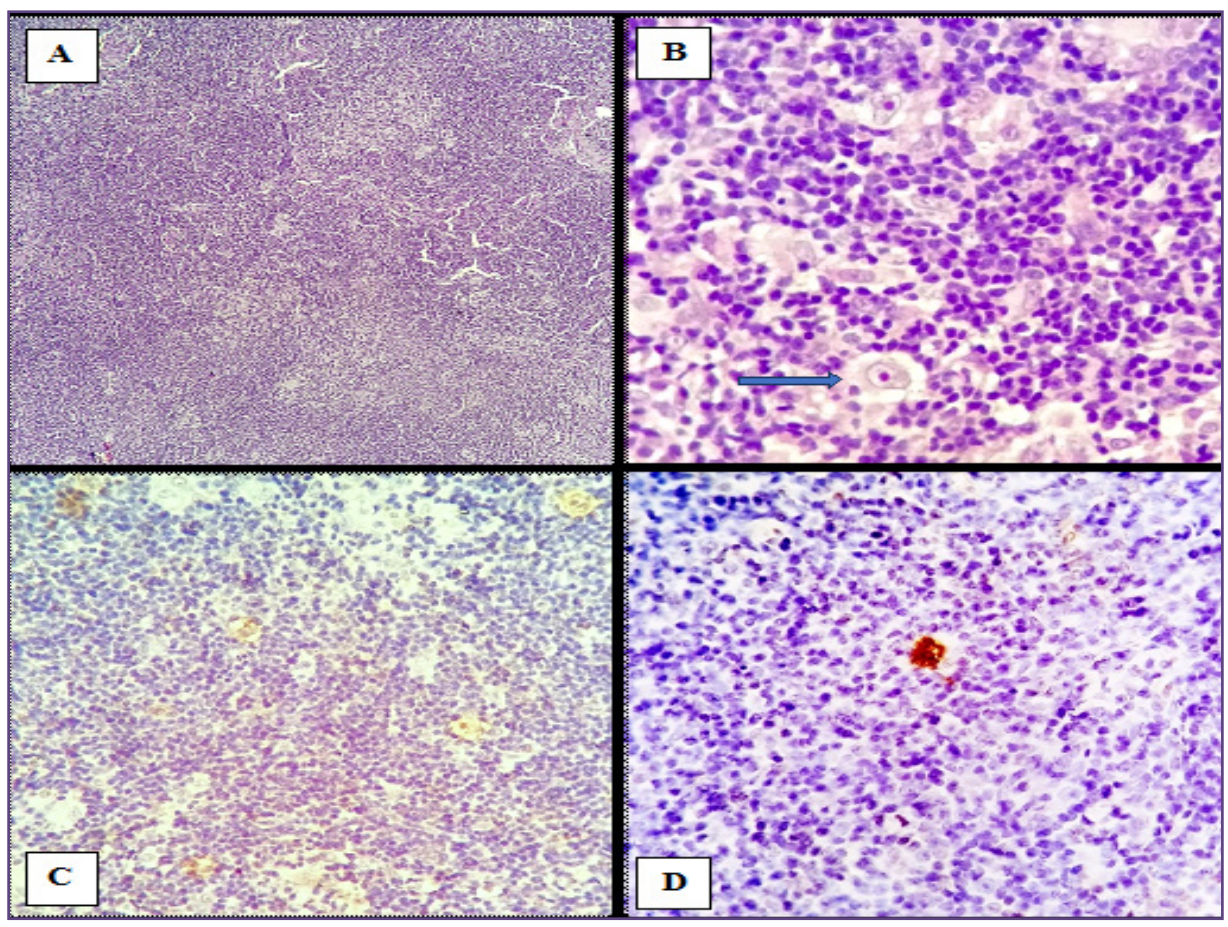

Fig. 3A: Lymphocyte rich HL (H\&E: X40 magnification), Fig. 3B: Lymphocyte rich HL (H\&E: X600 magnification) RS/H cell surrounded by abundant lymphocytes, Fig. 3C: Lymphocyte rich HL (EBV-LMP1: X400 magnification), Fig 3D: Lymphocyte rich HL (EBV-LMP1: X600 magnification) Single RS/H cell showing positivity for EBV-LMP1. 


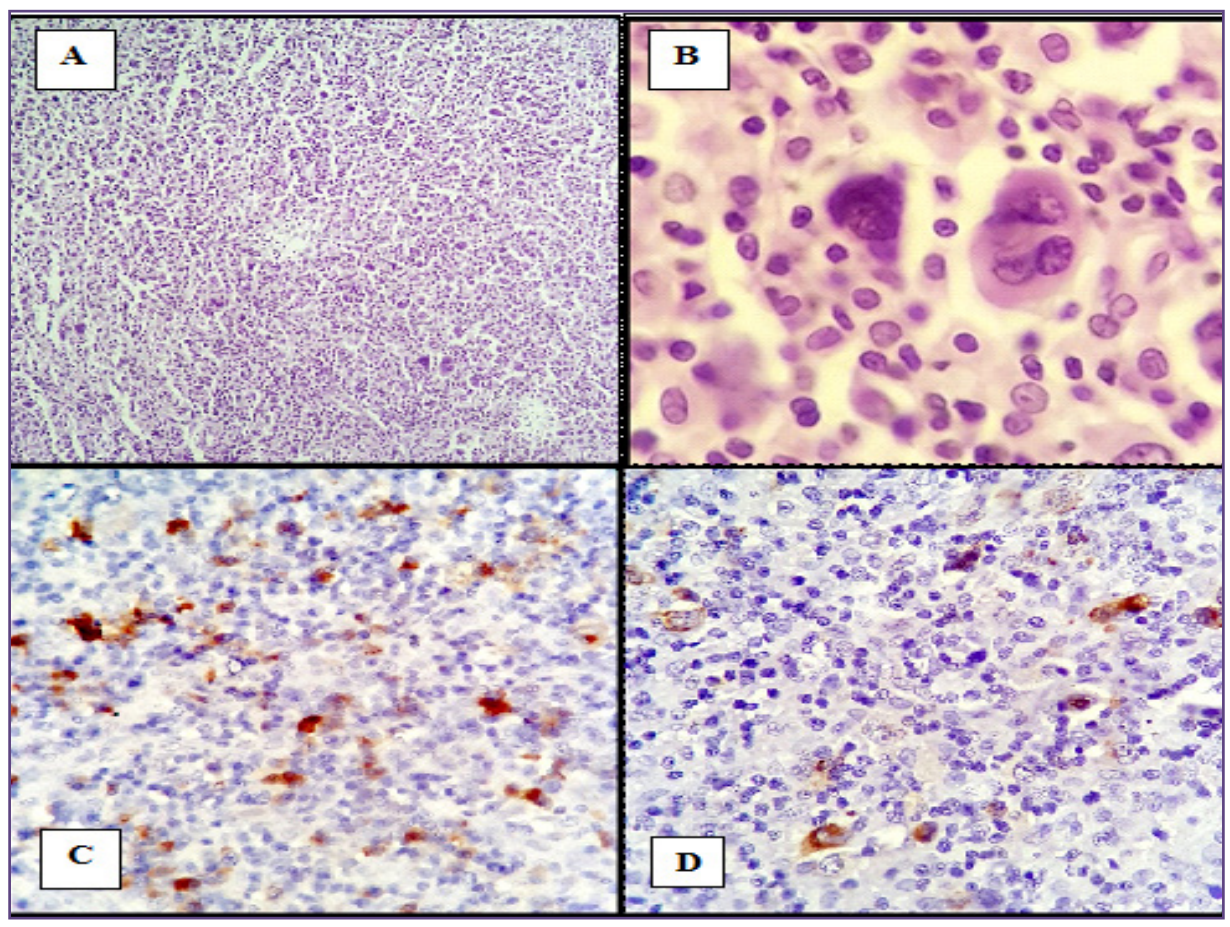

Fig. 4A: Lymphocyte depleted HL, H\&E: X40 magnification, Fig. 4B: Lymphocyte depleted HL (H\&E: X600 magnification) RS/H cells with bizarre cytologic features, Fig. 4C: Lymphocyte depleted HL (CD15: X 400 magnification) RS/H cells showing positivity for CD15, Fig. 4D: Lymphocyte depleted HL (EBV-LMP1: X600 magnification) RS/H cells positive for EBV-LMP1.

\section{Discussion}

$\mathrm{HL}$ is a malignant disease of lymphoid tissue contributing $<1 \%$ of all de novo neoplasms occurring worldwide every year. EBV has been postulated as a causative agent in the disease process. Up to $100 \%$ of cHL in developing countries can be attributed to EBV though differences exist between rural and urban areas. LMP1 is a surrogate biomarker of EBV infection. Thus, the aim of this study was to study the expression of LMP1 in various subtypes of HL.

Demographic profile In the present study the age of patients ranged from 5-55years with a median age of 18years however, we found a lower median age of presentation as compared to other Indian studies by Jain et $\mathrm{al}^{[9]}$ (32years), Goswami et $\mathrm{al}^{[10]}$ (34years) and Patkar et $\mathrm{al}^{[11]}(35$ years); this may be because of limited sample size and time frame. Majority of the cases occurred in males (76.92\%), while females constituted $23.08 \%$ with $\mathrm{M}: \mathrm{F}$ ratio of 3.3:1. MCHL was the commonest subtype and occurred more commonly in males than females, cases of NSHL, LRHL and LDHL too were male predominant. These findings are similar to the various studies which also show predominance in males except NSHL variant in which equal incidence is found in males and females. ${ }^{[12-}$ ${ }^{15}$ These can be explained by the social status of patients, since majority of the patients in the present study belonged to lower middle \& lower economical strata and younger age group $(<15$ years $)$ wherein there is increased exposure to infectious agents early in childhood due to less hygienic environmental conditions, multiple playmates and siblings, overcrowded dwellings thus leading to increased risk of development of classical HL ${ }^{[16]}$

Classical HL in western population shows a bimodal distribution with first peak in second to third decade and second peak in the sixth decade. ${ }^{[17]}$ No such distribution was seen in the present study or other Indian studies.

Clinical profile In the present study, B symptoms were recorded in $50 \%$ cases. Study by Goswami et al ${ }^{[10]}$ and Chandi et al ${ }^{[18]}$ reported frequency of B symptoms to be $79.17 \%$ and $73 \%$ respectively.

However, Dinand et al ${ }^{[7]}$ found B symptoms in $61.5 \%$ patients which is comparable to that seen in the present study. In the current study, palpable LAP was found to be consistently present in all patients, most common site being cervical nodes. Similar results were seen in study by Jain et al ${ }^{[9]}(92 \%)$. This may suggest a higher burden of disease at the time of diagnosis. Pallor was noted in $64 \%$ cases in the present study. Comparable results were reported by Dinand et al ${ }^{[7]}(61.9 \%)$ and Goswami et al ${ }^{[10]}(70.83 \%)$. More than $50 \%$ patients $(88.5 \%)$ had LAP for less than 
one year. Bulky disease was seen in $19.2 \%$ cases which is lesser compared to other studies. Jain et al [9] found bulky disease in $42 \%$ patients while Diehl et al ${ }^{[19]}$ found even higher incidence of $58-68 \%$.

Disease distribution In the present study, MCHL comprised of 20 out of 26 cases $(77 \%)$. This was followed by LDHL comprising of 03 out of 26 cases(11.5\%), NSHL, 02 out of 26 cases and LRHL 01 out of 26 cases. Goswami et al ${ }^{[10]}$ studied a total of 48 cases from North Eastern part of India and found MCHL as the commonest subtype (45.83\%) followed by NSHL (33.33\%), LDHL $(4.17 \%)$ and LRHL (2.08\%). Jain et al ${ }^{[9]}$ in their study from Western part of India studied a total of 125 patients and found MCHL as the most common subtype comprising $57 \%$, followed by NSHL and LRHL in 32\%, 02\%. Dinand et al ${ }^{[7]}$ studied 145 cases from Northern India and found MCHL in $72.4 \%$ cases, NSHL in $22.8 \%$ cases, NLPHL in $1.4 \%$ cases, LRHL and LDHL in $0.7 \%$ cases.

While MCHL remains the predominant subtype in Indian subcontinent, data from western countries have shown nodular sclerosis as the predominant subtype of cHL. Herling et al ${ }^{[20]}$ studied 577 cases of HL and found NSHL in $80.07 \%$ cases, followed by MCHL in $19.41 \%$ cases and LDHL in $0.52 \%$ cases. Study by Jarett et al ${ }^{[21]}$ included 461 cases of classic HL (cHL) and found NSHL as the predominant subtype in $69.41 \%$, MCHL in $22.78 \%$, LRHL in $3.47 \%$ and LDHL in $0.65 \%$ cases. Thus the findings of the present study are similar to the rest of Indian studies which have shown MCHL as the predominant subtype of cHL particularly one by Dinand et al ${ }^{[7]}$, the difference from western data is quite striking where NS is the predominant subtype.

In the current study, $80.8 \%$ patients belonged to early stage, of which stage I were $65.4 \%$ and stage II were $15.4 \%$ whereas $19.2 \%$ patients belonged to advanced stage with $15.4 \%$ in stage III and $3.8 \%$ in stage IV.

\section{Immunohistochemical expression of EBV in HL}

EBV association with cHL shows geographical variation. Available data suggests an association of EBV to be 70 $100 \%$ in developing countries and $30-50 \%$ in developed countries, by combined IHC for LMP1 and in situ hybridisation methods. ${ }^{[22-32]}$

In the present study 19 out of 26 cases $(73.1 \%)$ were found to be positive for EBV by immunohistochemistry for LMP1 antigen. Naresh et al ${ }^{[4]}$ studied 110 cases of $\mathrm{cHL}$ and found EBV-LMP1 positivity of 51\%. Karnik et al ${ }^{[5]}$ in their study involving 100 cases of HL found LMP1 positivity in $82 \%$ cases. Another study by Gala et al ${ }^{[33]}$ found EBV positivity of $51 \%$ however they employed EBER-ISH as a method to detect infection. All three above studies were conducted in adult HL cases. In the paediatric age group Dinand et al ${ }^{[7]}$ have found EBV positivity in as high as $90.3 \%$ cases. India being a developing country therefore proves to be carrying a remarkably high association of EBV with HL.

Data from western countries has shown a lesser association with EBV. Study by Jarrett et al ${ }^{[21]}$ including $461 \mathrm{HL}$ cases found EBV positivity in only $33.41 \%$ cases. Glaser et al [34] while studying diverse racial/ethnic group of 1032 patients found overall EBV positivity of $23 \%$ in whites, $28 \%$ in blacks, $46 \%$ in Hispanics and $40 \%$ in Asian/Pacific Islander patients. Study by Herling et al ${ }^{[20]}$ reported EBV positivity by LMP1 in $21 \%$ cases of HL.

Similarly, Cickusic et al ${ }^{[35]}$ also found EBV positivity in only $38.3 \%$ of the patients studied.

\section{Correlation of EBV positivity with various subtypes of HL}

Mixed cellularity HL: In the present study, 14 out of 20 $(70 \%)$ MCHL cases were positive for EBV LMP1. Naresh et al ${ }^{[4]}$ found EBV positivity in $86 \%$ MCHL cases, whereas Karnik et al ${ }^{[5]}$ have reported $79 \%$ positive cases. Even higher positivity of EBV in MCHL was seen in the study by Dinand et al ${ }^{[7]}(97.1 \%)$.

Among the western studies, one by Herling et al ${ }^{[20]}$ found EBV positive MCHL in 39\% patients only. Cickusic et al ${ }^{[35]}$ have reported EBV association in $25.6 \%$ HL patients whereas Jarrett et al ${ }^{[21]}$ reported it in $22.8 \%$ cases. Glaser et al ${ }^{[34]}$ found $\mathrm{EBV}$ positive MCHL in $59.3 \%$ whites, 42.1\% blacks, 74.5\% Hispanics and 80\% Asian/Pacific islanders. From the above results it is evident that EBV is more frequently associated with MCHL in the developing countries than the developed.

Nodular sclerosis HL: In the current study, EBV association was noted in both cases of NSHL (however, sample size too small to calculate percentage). Naresh et al ${ }^{[4]}$ found EBV association in $67 \%$ cases while Karnik et al ${ }^{[5]}$ found it in $86 \%$ cases. Dinand et al ${ }^{[7]}$ reported EBV in $97 \%$ NSHL cases. Study by Herling et al ${ }^{[20]}$ reported $17 \%$ positivity of EBV in NS subtype, while Jarrett et $\mathrm{al}^{[21]}$ and Cickusic et $\mathrm{al}^{[35]}$ have reported $69.4 \%$ and $66.7 \%$ respectively.

Lymphocyte rich HL: In the present study we had a single case of LRHL and it was positive for EBV-LMP1, but sample size being low further extrapolation was not possible. Dinand et al ${ }^{[7]}$ and Naresh et al ${ }^{[4]}$ found a high positivity of $100 \%$ and $81 \%$ in this subtype, respectively. 
In the western scenario, EBV association was found to be low. Study by Jarrett et al ${ }^{[21]}$ have reported a positivity of only $3.5 \%$.

Lymphocyte depleted HL: EBV association with LDHL in the present study was found to be two out of three cases. Karnik et al ${ }^{[5]}$ reported it to be $75 \%$ whereas Dinand et al [7] found $100 \%$ positivity in this subtype. Jarrett et al [21] in their study found only $0.65 \%$ EBV positivity in LDHL whereas Cickusic et al ${ }^{[35]}$ and Herling et al ${ }^{[20]}$ have found it to be $5.1 \%$ and $67 \%$ respectively.

\section{Correlation of EBV with stage of disease}

Stage of the disease is an independent prognostic factor in HL. EBV-LMP1 positivity was found in 13 out of 17 cases (76.5\%) belonging to stage I disease. In stage II, two out of four cases were positive, in stage III all four cases were positive for EBV-LMP1, while single case which belonged to stage IV was negative. Due to limitation of number of cases a conclusive remark regarding correlation of EBV with stage is not possible. We could not find Indian studies correlating EBV status and stage of disease.

In the study by Jarrett et al, ${ }^{[21]} \mathrm{EBV}$ association in stage I, II, III and IV was found to be $30.3 \%, 26.2 \%, 23.4 \%$ and $20 \%$ respectively while Herling et al ${ }^{[20]}$ reported EBV positivity as $40 \%, 13 \%, 28 \%$ and $27 \%$ in the respective stages.

Majority of the patients in the present study belonged to early stage disease (stage I\&II). The present study highlights that HL in Indian context is predominantly a disease of young males, with MCHL as the commonest subtype and presentation at an early stage.

\section{Conclusion}

The present study included 26 newly diagnosed cases of HL. They were all staged clinically according to the Ann arbor classification and diagnosis was confirmed on lymph node excision biopsy. Patients age ranged from 5-55years with a median age of 18 years. A loss of bimodal pattern of distribution was observed. Majority of the cases occurred in males $(76.92 \%)$ with a M:F ratio of 3.3:1. Palpable LAP was found in $100 \%$ patients, followed by pallor in $64 \%$ cases, B symptoms in 50\% cases and nodal pain in $30.8 \%$. Bulky disease was noted in 19.2\% cases. More than half of the patients had LAP for less than a year $(88.5 \%)$. Most of the patients presented with stage I $(65.4 \%)$, followed by stage II\&III (15.4\%) and only $3.8 \%$ with stage IV suggesting a lower stage of presentation among Indian patients than western patients. MCHL comprised of 20/26 cases $(76.9 \%)$, followed by LDHL subtype 03/26 (11.5\%), NSHL 02/26 (7.7\%) and LRHL 01/26 (3.8\%). The median age of presentation was 17years in MCHL, 11.5 years in NSHL, 14years in LRHL and 34 years in LDHL subtype. Male predominance was seen in MCHL, LRHL \& LDHL while NSHL had equal incidence among males and females. EBV by LMP1 was detected in total 19/26 cases (73.1\%). MCHL showed an association with EBV in 14/20 cases $(70 \%)$ and a higher EBV positivity in early stage of the disease.

This is the only study from North India describing association of EBV with HL, in all age groups, highlighting the demographic variants and its relationship with EBV association.

Study limitations: Due to time constraints of dissertation, low input of institutional cases and prospective nature of the study a sample size of 25 cases was considered. However, data needs more support with larger studies to ascertain the association in all subtypes and with different stages.

Conflicts of interest: "The Author(s) declare that they have no conflict of interest."

\section{References}

1. Castillo J, Beltran B, Miranda R, Paydas S, Winer E, Butera J. Epstein-Barr Virus-positive Diffuse Large B-Cell Lymphoma of the elderly: What we know so far. The Oncologist. 2011;16(1):87-96.

2. Anagnostopoulos I, Herbst H, Niedobitek G, Stein H. Demonstration of monoclonal EBV genomes in Hodgkin's disease and Ki-1 positive anaplastic large cell lymphoma by combined Southern and in situ hybridisation. Blood.1989;74:810-6.

3. Radha K, Shanthi P, Madhavan M, Senthamarai A. Study of association of Epstein-Barr virus with Hodgkin's disease. Indian J Pathol Microbiol. 1997;40(3):351-4.

4. Naresh KN, Johnson J, Srinivas V, Soman C, Saikia T, Advani $\mathrm{S}$ et al. Epstein-Barr virus association in classical Hodgkin's disease provides survival advantage to patients and correlates with higher expression of proliferation markers in Reed-Sternberg cells. Annals of Oncology.2000;11:91-6.

5. Karnik S, Srinivasan B, Nair S. Hodgkin's lymphoma: Immunohistochemical features and its association with EBV LMP-1. Experience from a South Indian hospital. Pathology. 2003;35(3):207-11

6. Rajalakshmi T, Payal K, Makhija P, Karuna V. Epstein- Barr virus in Hodgkin's lymphoma-Incidence and prognostic implications. Indian Journal of Medical and Paediatric Oncology. 2006;27(1):23-6.

7. Dinand V, Dawar R, Arya LS, Unni R, Mohanty B, Singh R et al. Hodgkin's lymphoma in Indian children: prevalence and significance of Epstein-Barr virus detection in Hodgkin's and Reed-Sternberg cells. Eur J Cancer. 2007;43(1):161-8. 
8. Gulley M, Glaser S, Craig F, Borowitz M, Mann R, Shema $\mathrm{S}$ et al. Guidelines for interpreting EBER in Situ Hybridisation and LMP1 immunohistochemical tests for detecting Epstein-Barr virus in Hodgkin lymphoma. Am J Clin Pathol.2002;117:259-67.

9. Jain H, Sengar M, Nair R, Menon H, Laskar S, Shet T et al. Treatment results in advanced stage Hodgkin's lymphoma: A retrospective study. J Postgrad Med.2015;61(2):88-91.

10. Goswami B, Sarkar S, Chakraborti S, Mondal S, Roy A, Deb A. Clinicopathologic profile of Hodgkin's lymphoma in a rural medical college. Indian $\mathrm{J}$ Hematol Blood Transfus.2008;24(4):166-9.

11. Patkar N, Mehta J, Kulkarni B, Pande R, Advani S, Borges A. Immunoprofile of Hodgkin's lymphoma in India. Indian Journal of Cancer. 2008;45(2):59-63.

12. Au WY, Gascoyne RD, Gallagher RE, LeN, KlasaRD, Liang R. Hodgkin's lymphoma in Chinese migrants to British Columbia: a 25-year survey. Annals of Oncology. 2004;15(4):626-30.

13. Morton LM, Wang SS, Devesa SS, Hartge P, Weisenburger DD, Linet MS. Lymphoma incidence patterns by WHO subtype in the United States, 1992-2001.Blood. 2006;107(1):265-76.

14. Shimabukuro-Vornhagen A, Haverkamp H, Engert A, Balleisen L, Majunke P, Heil G et al. Lymphocyte-rich classical Hodgkin's lymphoma: clinical presentation and treatment outcome in 100 patients treated within German Hodgkin's Study Group trials. J Clin Oncol. 2005;23(24):5739-45.

15. Slack GW, Ferry JA, Hasserjian RP, Sohani AR, Longtine JA, Harris NL et al. Lymphocyte depleted Hodgkin lymphoma: an evaluation with immunophenotyping and genetic analysis. Leuk Lymphoma. 2009;50(6):937-43.

16. Swerdlow AJ. Epidemiology of Hodgkin's disease and nonHodgkin's lymphoma. Eur J Nucl Med Mol Imaging.2003;30 Suppl 1:3-12.

17. Jarrett R, Krajewski A, Angus B, Freeland J, Taylor P, Taylor G et al. The Scotland and Newcastle epidemiological study of Hodgkin's disease: Impact of histopathological review and EBV status on incidence estimates. J Clin Pathol.2003;56(11):811-6.

18. Chandi L, Kumar L, Kochupillai V, Dawar R, Singh R. Hodgkin's disease: a retrospective analysis of 15 years experience at a large referral centre. Natl Med J India.1998;11(5):212-7.

19. Diehl V, Franklin J, Pfreundschuh M, Lathan B, Paulus U, Hasenclever D et al. Standard and Increased-Dose BEACOPP Chemotherapy Compared with COPP-ABVD for Advanced Hodgkin's Disease. N Engl J Med.2003;348:2386-95.

20. Herling M, Rassidakis G, Medeiros L, Vassilakopoulos T, Kliche K, Nadali G et al. Expression of Epstein-Barr virus latent membrane protein-1 in Hodgkin and Reed- Sternberg cells of classical Hodgkin's lymphoma: associations with presenting features, serum interleukin 10 levels, and clinical outcome. Clin Cancer Res. 2003;9(6):2114-20.

21. Jarrett RF, Stark GL, White J, Angus B, Alexander FE, Krajewski AS et al. Impact of tumor Epstein-Barr virus status on presenting features and outcome in age-defined subgroups of patients with classic Hodgkin lymphoma: a population-based study. Blood. 2005;106(7):2444-51.

22. Glaser SL, Lin RJ, Stewart SL, Ambinder RF, Jarrett RF, Brousset $\mathrm{P}$ et al. Epstein Barr virus associated Hodgkin's disease: Epidemiologic characteristics in international data. Int J Cancer.1997;70:375-82.

23. Jarrett AF, Armstrong AA, Alexander E. Epidemiology of EBV and Hodgkin's lymphoma. Ann Oncol. 1996; 7 Supp14: 5-10.

24. Huh J, Park C, Juhng S, Kim CE, Poppema S, Kim C. A pathologic study of Hodgkin's disease in Korea and its association with Epstein-Barr virus infection. Cancer.1996;77:949-55.

25. Zarate-Osorno A, Roman L, Kingma DW, Meneses-Garcia A, Jaffe ES. Hodgkin's disease in Mexico. Prevalence of Epstein-Barr virus sequences and correlations with histologic subtype. Cancer.1995;75:1360-6.

26. Monterroso V, Zhou Y, Koo S, Glackin C, Bujan W, Medeiros LJ. Hodgkin's disease in Costa Rica: A report of 40 cases analyzed for Epstein-Barr virus. Am J Clin Pathol.1998;109(5):618-24.

27. Leoncini L, Spina D, Nyong'o A, Abinya O, Minacci C, Disanto A et al. Neoplastic cells of Hodgkin's disease show differences in EBV expression between Kenya and Italy. Int J Cancer.1996;65:781-4.

28. Weinreb M, Day PJ, Niggli F, Powell JE, Raafat F, Hesseling $\mathrm{PB}$ et al. The role of Epstein-Barr virus in Hodgkin's disease from different geographical areas. Arch Dis Child.1996;74(1):27-31.

29. Tomita Y, Ohsawa M, Kanno H, Hashimoto M, Ohnishi A, Nakanishi $\mathrm{H}$ et al. Epstein-Barr virus in Hodgkin's disease patients in Japan. Cancer.1996;77:186-92.

30. Chan JK, Yip TT, Tsang WY, Lau WH, Wong CS, Ma VW. Detection of Epstein-Barr virus in Hodgkin's disease occurring in an Oriental population. Hum Pathol. 1995;26(3):314-8.

31. Belkaid MI, Briere J, Djebbara Z, Beldjord K, Andrieu JM, Colonna P. Comparison of Epstein-Barr virus markers in Reed-Sternberg cells in adult Hodgkin's disease tissues from an industrialized and a developing country. Leuk Lymph.1995;17:163-8.

32. Gulley ML, Eagan PA, Quintanilla-Martinez L, Picado AL, Smir BN, Childs C et al. Epstein-Barr virus DNA is abundant and monoclonal in the Reed-Sternberg cells of Hodgkin's disease: Association with mixed cellularity subtype and Hispanic American ethnicity. Blood.1994; 83(6):1595-602. 
33. Gala R, Gandhi J, Gupta G, Grover S, Sharma A, Pasricha S et al. Study of association of Epstein-Barr virus in lymphomas by Epstein-Barr virus-encoded RNA in situ hybridization: An Indian perspective from a tertiary care cancer institute. Indian J Pathol Microbiol. 2017;60(3):341-9.

34. Glaser SL, Gulley ML, Clarke CA, Keegan TH, Chang ET, Shema SJ et al. Racial/ethnic variation in EBV-positive classical Hodgkin lymphoma in California populations. Int J Cancer.2008;123(7):1499-507.

35. Cickusic E, Mustedanagic-Mujanovic J, Iljazovic E, Karasalihovic Z, Skaljic I. Association of Hodgkin's Lymphoma with Epstein Barr Virus Infection. Bosnian Journal of Basic Medical Sciences.2007;7(1):58-65.

*Corresponding author:

Dr. Sarika Singh, 97B Block C Expressview Apartments, Sec 105, Noida,India

Email: sarikasingh97b@gmail.com

Date of Submission : 21/04/2020

Date of Acceptance : 29/05/2020

Financial or other Competing Interests: None.

Date of Publication : 30/06/2020 